\title{
PEMBINAAN KEMAMPUAN MENULIS DONGENG BAGI GURU TK AISYIYAH 01 KOTA MEDAN
}

\author{
Abdurahman Adisaputera ${ }^{1}$, Fitriani Lubis ${ }^{1}$, Trisnawati Hutagalung ${ }^{1}$ \\ Fakultas Bahasa dan Seni, Universitas Negeri Medan, Medan, Indonesia \\ *Penulis Korespondensi: abas_750@yahoo.co.id
}

\begin{abstract}
Abstrak
Menulis adalah suatu kegiatan memproduksi hasil olah pikir. Tujuan pelaksanaan kegiatan ini adalah untuk meningkatkan kemampuan menulis dongeng yang dimiliki guruDengan meningkatnya kemampuan menulis dongeng akan menjadi langkah awal seorang guru agar dapat mengembangkan kemampuan mendongeng yang dimiliki. Karena, dengan dongeng yang ditulisnya sendiri, guru dengan mudah melatih diri agar lebih mahir dalam menulis dongeng. Untuk itu diperlukan tindak lanjut dalam hal ini pembinaan menulis dongeng bagi guru TK Aisyiyah 01 Kota Medan. Metode yang dilakukan dalam pembinaan menulis dongeng adalah metode pelaksanaan dengan 3 tahapan yaitu tahap workshop, tahap pembimbingan dan tahap pembuatan laporan hasil kegiatan, juga metode pendekatan yaitu metode pendidikan, metode pelatihan dan praktik, metode bimbingan dan praktik. Hasil kegiatan pembinaan menulis dongeng tersebut mendapat respon yang positif dan antusiasme kelompok sasaran. Seluruh peserta merasakan banyak manfaat terhadap pembinaan kemampuan menulis dongeng tersebut. Kemampuan itu dapat di lihat melalui dongeng yang ditulis guru secara individu yang dijadikan satu buku berisikan kumpulan dongeng yang telah ditulis oleh masing-masing guru. Dengan adanya luaran laporan pengabdian ini maka guru-guru dapat memanfaatkannya untuk menambah ilmu sebagai bahan acuan pembelajaran.
\end{abstract}

Kata Kunci : Pembinaan; Kemampuan; Menulis dongeng; Guru TK.

\begin{abstract}
Writing is an activity to produce the results of thinking. The purpose of this activity is to improve the ability of writing fairy tales owned by teachers. Because, by the fairy tale that he wrote by himself, the teacher easily trains himself to be more proficient in writing fairy tales. For this reason, a follow-up is needed in fostering of writing fairy tales for kindergarten Aisyiyah 01 Medan City teachers. The method used in fostering of writing a fairy tale is an implementation method with 3 stages, they are: the workshop phase, the guidance stage and the stage of making reports on the results of activities, as well as the approach methods namely educational methods, training methods and practices, guidance methods and practice. The results of the fairy tale writing coaching activity received a positive response and enthusiasm from the target group. All participants get many benefits towards fostering the ability to write the fairy tale. That ability can be seen through a fairy tale which has written by the teacher individually made into a book containing a collection of fairy tales written by each teacher. With this outcome report, the teachers can use it to add knowledge as a reference for learning.
\end{abstract}

Keywords: Coaching; Ability; Writing Fairy Tales; Kindergarten Teachers.

\section{PENDAHULUAN}

Kemampuan berbahasa mencakup 4 (empat) aspek yaitu menyimak, berbicara, membaca, dan menulis. Berdasarkan keempat keterampilan berbahasa tersebut, keterampilan menulis merupakan keterampilan yang kompleks karena penulis dituntut untuk dapat menyusun dan mengorganisasikan isi tulisan serta menuangkannya dalam bahasa tulis. Akhadiah, dkk (dalam Sari, 2013) menerangkan bahwa menulis juga berarti mengorganisasikan gagasan secara sistematik serta mengungkapkannya secara tersurat. Dengan demikian, kegiatan menulis tersebut dapat menjelaskan permasalahan yang semula samar bagi diri si penulis. Maka dari itu, dapat disimpulkan bahwa menulis adalah suatu kegiatan memproduksi hasil olah pikir. Sejalan dengan hal tersebut Resmini (dalam Nurfadillah, 2018) "menulis merupakan keterampilan yang sulit diajarkan". Karena, menulis adalah proses yang membutuhkan kreativitas dan daya imajinasi tinggi dalam menuangkan sebuah ide atau gagasan dari bentuk lisan menjadi sebuah tulisan. Djamaris (2002:4) mengemukakan jenis karya sastra yang tergolong prosa terbagi atas tiga macam, yaitu: (1) carito atau cerita, (2) kaba, (3) undang-undang, dan (4) tambo. Jenis karya sastra yang tergolong cerita ini merupakan cerita pendek atau cerita sederhana, salah satunya dongeng. Djamaris juga menyatakan dongeng adalah cerita tentang suatu hal yang tidak pernah terjadi dan hanya cerita khayal 
semata. Mulyoto (2006, p. 9-11) manfaat menulis antara lain: (1) menulis mempunyai kepuasan yang bersifat kebatinan, (2) menulis dapat meningkatan pengembangan intelektual, (3) menulis dapat memberikan pengalaman dan informasi serta pengetahuan, dan (4) menulis dapat menambah kearifan, kedewasaan, pengetahuan, bahkan juga keterampilan. Meningkatkan kemampuan menulis dongeng adalah langkah awal seorang guru agar dapat mengembangkan kemampuan mendongeng yang dimiliki. Karena, dengan dongeng yang ditulisnya sendiri, guru dengan mudah melatih diri agar lebih mahir dalam mendongeng. Langkah awal yang harus diketahui guru adalah unsur intrinsik sebuah dongeng, yaitu

1) Tema adalah ide pokok dari cerita dan merupakan patokan untuk membangun suatu cerita.

2) Alur adalah jalan cerita yang diurutkan berdasarkan sebab akibat maupun berdasarkan urutan waktu.

3) Penokohan adalah proses penampilan tokoh dengan pemberian watak dan juga sifat.

4) Latar adalah salah satu unsur intrinsik pembentuk cerita yang menunjukkan dimana dan kapan rangkaian rangkaian cerita itu terjadi.

5) Amanat adalah pesan yang ingin disampaikan pengarang kepada pembaca melalui cerita yang dibuat.

Adapun cara menulis dongeng secara umum adalah sebagai berikut:

1) Tentukan jenis dongeng yang akan dibuat

2) Pikirkan setting waktu dan tempat. Kekayaan latar budaya di Indonesia bisa menjadi referensi agar mengenalkan Indonesia.

3) Setelah itu, buat jalan cerita yang menonjolkan keajaiban-keajaiban.

4) Gunakan kalimat yang mudah dipahami anak-anak, hindari penggunaan kalimat multitafsir yang membuat anak-anak tidak paham.

5) Perhatikan EYD yang digunakan dalam tulisan.

6) Manfaatkan referensi dongeng yang sudah diterbitkan oleh orang lain di media massa.

7) Sisipkan pesan moral di dalam dongeng, hindari pesan secara verbal, karena anak-anak kurang suka pada cerpen yang bersifat menggurui.

Berdasarkan hasil observasi yang dilakukan pengabdi terhadap TK Aisyiyah 01 Kota Medan, bahwa permasalahan khusus yang dihadapi mitra adalah:

1) guru-guru $\mathrm{TK}$ kurang memahami teori dongeng secara terperinci

2) guru-guru TK Aisyiyah 01 Kota Medan membutuhkan pembinaan untuk mengembangkan pengetahuan mengenai cara menulis dongeng dengan baik dan benar

3) guru-guru TK Aisyiyah 01 Kota Medan membutuhkan pembinaan kemampuan menulis dongeng agar dapat menggunakan dongeng hasil tulisan sendiri untuk melatih kemahiran mendongeng sehingga dapat dijadikan sebagai alat untuk proses pembelajaran anak usia dini.
Dalam hal itu, melihat keadaan tersebut, TK Aisyiyah 01 Kota Medan layak diberikan pembinaan kemampuan menulis dongeng dengan tujuan membangkitkan antusiasme guru menggunakan dongeng sebagai alat pembelajaran di kelas. Dikarenakan keberadaan dongeng semakin punah, penyebab utamanya adalah jarangnya para guru mengenalkan dongen kepada anak didik dengan cara menggunakan dongeng sebagai media dalam pembentukan moral dan pribadi anak didik ketika di kelas. Padahal pada dasarnya, dunia pendidikan memerlukan dongeng sebagai media pemberi suri tauladan bagi anak - anak. Dongeng mengandung nilai kearifan lokal yang berpotensi mengenalkan budaya daerah kepada anak didik agar mereka mampu menghargai dan melestarikan budaya tersebut. Tujuan pelaksanaan kegiatan ini adalah untuk meningkatkan kemampuan menulis dongeng yang dimiliki guru, sehingga dengan dongeng yang dihasilkan membuat guru lebih mudah mengembangkan kemampuan mendongeng yang nantinya akan diaplikasikan dalam pembelajaran di kelas.

\section{BAHAN DAN METODE}

\subsection{Metode Pelaksanaan}

Kurangnya kemahiran guru TK dalam menulis dongeng mempengaruhi antusiasme guru menggunakan dongeng sebagai pembelajaran yang variatif di dalam kelas. Pengabdian ini dimulai dengan penerapan materi dongeng secara terperinci, termasuk di dalamnya cara menulis dongeng yang baik dan benar juga hal-hal yang harus dikuasai ketika ingin menulis dongeng, kemudian dilanjutkan dengan pelatihan menulis dongeng pada semua guru peserta pengabdian sampai diperolehnya luaran yang diharapkan yaitu laporan berupa buku berisi kumpulan dongeng hasil tulisan masing-masing guru TK Aisyiyah 01 Kota Medan. Adapun rincian tahapan kegiatan pengabdian ini adalah sebagai berikut:

1. Tahapan Workshop

Pada tahapan ini, guru diberikan materi tentang dongeng scara terperinci, dimulai dari pentingnya dongeng dalam dunia kependidikan, hal-hal yang harus dikuasai dalam menulis dongeng, hingga cara menulis dongeng dengan baik dan benar.

\section{Tahapan pembimbingan}

Pembimbingan dalam melakukan kegiatan mendongeng ini dilakukan sampai tercapainya luaran kegiatan yang diharapkan yaitu berupa buku yang berisi kumpulan dongeng hasil tulisan masing-masing guru. Dalam proses pembimbingan ini, guru-guru akan didampingi oleh tim instruktur kegiatan mendongeng.

\section{Tahapan pembuatan laporan hasil kegiatan}

Tahapan ini adalah tahapan terakhir dari rangkaian kegiatan pengabdian masyarakat yang akan dilakukan. Tahapan ini adalah tahapan pembuatan laporan hasil kegiatan oleh tim pengabdian masyarakat. Tim pengabdian masyarakat akan menyusun laporan hasil kegiatan yang sudah dilakukan dan mengarsip luaran kegiatan laporan serta lampiran-lampiran lain seperti 
foto-foto kegiatan, sertifikat kegiatan baik untuk peserta maupun istruktur, dan menyusun laporan pertanggungjawaban keuangan yang digunakan selama kegiatan berlangsung.

\subsection{Metode Pendekatan}

Metode pendekatan yang ditawarkan untuk menyelesaikan permasalahan prioritas adalah :

1. Metode pendidikan diberikan untuk menjelaskan hal-hal yang harus dikuasai guru dalam menulis dongen dan cara menulis dongeng dengan baik dan benar

2. Metode latihan dan praktik diberikan untuk melatih dan mempraktikkan langsung bagaimana langkahlangkah pembinaan menulis dongeng

3. Bimbingan dan pendampingan dalam penerapan menulis dongeng untuk mendapatkan hasil yang baik sesuai dengan yang diharapkan oleh mitra.

\section{HASIL DAN PEMBAHASAN}

Pengabdian masyarakat program sekolah binaan di TK Aisyiyah 01 Kota Medan dilakukan karena kurangnya antusiasme guru untuk memanfaatkan dongeng sebagai pembelajaran yang variatif di dalam kelas. Pengabdian dilakukan dalam bentuk pembinaan, dimana di dalamnya terdapat pelatihan dan pembimbingan menulis dongeng hingga benar-benar mahir memproduksi tulisan dalam bentuk dongeng sesuai dengan ketentuan dongeng pada umumnya.

Program yang dilaksanakan mendapat respon positif dari kelompok sasaran, guru, kepala sekolah hingga anak didik. Hal tersebut terlihat dari antusiasme kelompok sasaran pada tahap-tahap yang dilakukan.

Kegiatan yang dilakukan akan dirincikan sebagai berikut.

\section{Pihak yang Terlibat}

Pihak yang terlibat dalam kegiatan pengabdian masyarakat ini adalah guru-guru TK Aisyiyah 01 Kota Medan, timpengusul, dan mahasiswa Jurusan Bahasa dan Sastra Indonesia.

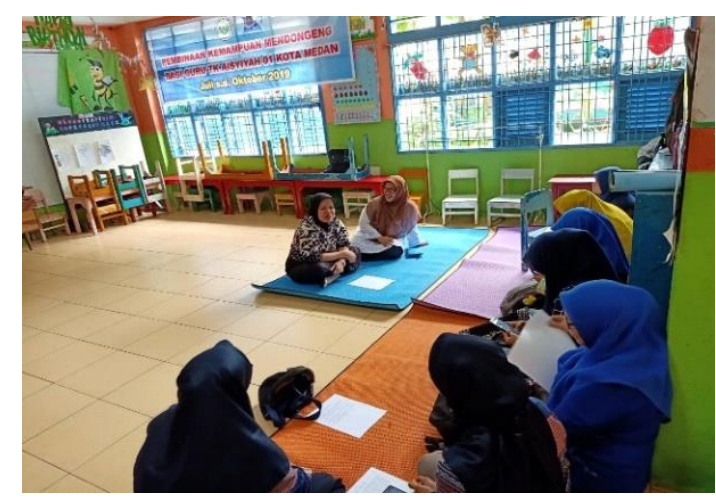

Gambar 1. Peserta yang Terlibat dan Tim Pengusul.

\section{Peran Peserta}

Peran peserta dalam kegiatan pengabdian ini menyediakan tempat untuk pendampingan pembinaan kemampuan menulis dongeng guru TK Aisyiyah 01 Kota Medan.Selain itu, peserta berperan aktif dalam kegiatan.

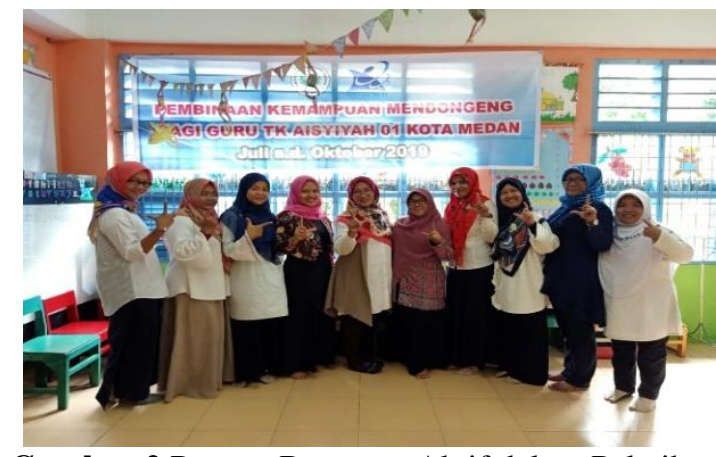

Gambar 2.Peserta Berperan Aktif dalam Pelatihan.

Model yang Diterapkan

Kegiatan pengabdian masyarakat Pembinaan Kemampuan Menulis Dongeng bagi Guru TK Aisyiyah 01 Kota Medan dilakukan dengan tahapan sebagai berikut:

\begin{tabular}{|c|c|c|c|}
\hline No & Tahapan & Kegiatan & Partisipasi Mitra \\
\hline 1 & Persiapan & $\begin{array}{l}\text { a) Observasi dan wawancara untuk } \\
\text { analisis situasi mengenai kemampuan } \\
\text { menulis dongeng guru TK Aisyiyah } 01 \\
\text { Kota Medan } \\
\text { b) Membangun komitmen bersama } \\
\text { dengan sekolah mitra. } \\
\text { c) Menentukan jadwal kegiatan, dan } \\
\text { d) Menyediakan segala keperluan sarana } \\
\text { dan prasarana dalam mendukung } \\
\text { terlaksananya kegiatan pengabdian } \\
\text { dengan baik. }\end{array}$ & $\begin{array}{l}\text { Menyiapkan data yang } \\
\text { berhubungan dengan hal-hal } \\
\text { yang diperlukan untuk } \\
\text { pembinaan kemampuan } \\
\text { menulis dongeng. }\end{array}$ \\
\hline 2 & Pelaksanaan & $\begin{array}{l}\text { a) Memberikan sosialisasi pada guru-guru } \\
\text { TK Aisyiyah } 01 \text { Kota Medan mengenai } \\
\text { hal-hal yang perlu dikuasai sebelum }\end{array}$ & $\begin{array}{l}\text { Menyediakan tempat } \\
\text { pelatihan dan berperan aktif }\end{array}$ \\
\hline
\end{tabular}




\begin{tabular}{|c|c|c|c|}
\hline & & $\begin{array}{l}\text { menulis dongeng hingga cara menulis } \\
\text { dongeng dengan baik dan benar-benar. } \\
\text { b) Pendampingan menulis dongeng }\end{array}$ & $\begin{array}{l}\text { selama } \\
\text { berlangsung }\end{array}$ \\
\hline 3 & Evaluasi dan Refleksi & $\begin{array}{l}\text { 1. Memberikan penilaian terhadap } \\
\text { kemampuan menulis dongeng guru } \\
\text { TK Aiyiyah 01 Kota Medan } \\
\text { 2. Berdasarkan masukan dari tim } \\
\text { pengusul, mitra kembali menguasai } \\
\text { cara menulis dongeng dengan baik } \\
\text { dan benar }\end{array}$ & $\begin{array}{l}\text { Mengetahui kemampuan } \\
\text { yang dimiliki dalam } \\
\text { menulis dongeng dan solusi } \\
\text { dalam meningkatkan } \\
\text { kemampuan renulis } \\
\text { dongeng }\end{array}$ \\
\hline 4 & Tindak Lanjut & $\begin{array}{l}\text { Semakin terampilnya mitra dalam menulis } \\
\text { dongeng. }\end{array}$ & $\begin{array}{l}\text { Terus berkomitmen untuk } \\
\text { mengasah kemampuan } \\
\text { menulis dongeng dengan } \\
\text { memproduksi } \\
\text { berbentuk dongeng. }\end{array}$ \\
\hline
\end{tabular}

Dari hasil yang didapatkan, dapat disimpulkan bahwa mita menyambut baik program pembinaan kemampuan menulis dongeng yang diberikan dan berdampak positif. Hal ini juga terlihat dari hasil tulisan guru pada saat dilakukan pendampingan, dimana peserta sangat fokus dalam menulis dongeng. Selain itu, kelompok sasaran mengakui bahwa kegiatan ini membawa banyak manfaat bagi guru, karena dengan mahirnya guru menulis dongeng, guru lebih antusiasme menggunakan dongeng dalam pembelajaran di kelas.

Peserta kegiatan juga menerangkan bahwa ada beberapa kendala yang cukup menghambat dalam menulis dongeng. Salah satunya adalah menentukan tema dalam penulisan dongeng. Namun, dengan pelatihan dan pembinaan yang dilakukan, kelompok sasaran tidak lagi kesulitan untuk menentukan tema karena sudah terlatih.

\section{KESIMPULAN}

Berdasarkan hasil kegiatan pembinaan kemampuan menulis dongeng guru TK Aisyiyah 01 Kota Medan yang telah dilaksanakan, maka dapat diambil kesimpulan sebagai berikut:

1) Pada saat tahap sosialisasi dilakukan, guru TK Aisyiyah 01 Kota Medan, guru fokus mendengarkan mengenai materi yang disampaikan, baik beupa unsur intrinsik dalam sebuah dongeng, juga cara menulis dongeng dengan baik dan benar.

2) Pada saat tahap pendampingan penulisan dongeng, guru fokus dan antusias dalam menulis dongeng.

3) Masalah yang timbul dalam kegiatan ini adalah menentukan tema dongeng yang akan diproduksi.

4) Rencana dan harapan guru TK ke depannya adalah agar program ini dapat menambah kreativitas guru dalam menulis sebuah dongeng agar membangkitkan semangat untuk menggunakan dongeng sebagai pembelajaran yang variatif di dalam kelas.

\section{UCAPAN TERIMA KASIH}

Kegiatan pengabdian kepada masyarakat ini didanai dari Lembaga Penelitian dan Pengabdian Universitas Negeri Medan.

\section{DAFTAR PUSTAKA}

Djamaris, Edwar. (2002). Pengantar Sastra Rakyat Minangkabau. Jakarta: Yayasan Obor Indonesia.

Mulyoto, M. (2006). Kiat menulis untuk media massa. Klaten: Sahabat.

Nurfadillah, Dilla dan Dian Indihadi. (2018). Penggunaan Media Cerita Bergambar dalam Penguraian Pesan pada Dongeng di Sekolah Dasar. Pedadidaktika: Jurnal IlmiahPendidikan Guru Sekolah Dasar, 5 (4), 217-225.

Sari, dkk. (2013). Peningkatan Menuliskan Kembali Dongeng dengan TeknikCirc Siswa Kelas VII.D SMPN 1Tanjung Emas Kabupaten Tanah Datar. Jurnal Pendidikan Bahasadan Sastra Indonesia, 39 (1), $241-317$. 